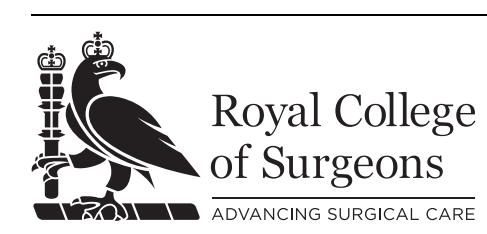

\section{Pandora's Box}

\section{TIM LANE}

Ann R Coll Surg Engl 2020; 102: 1-2

$10.1308 /$ rcsann.2019.0175

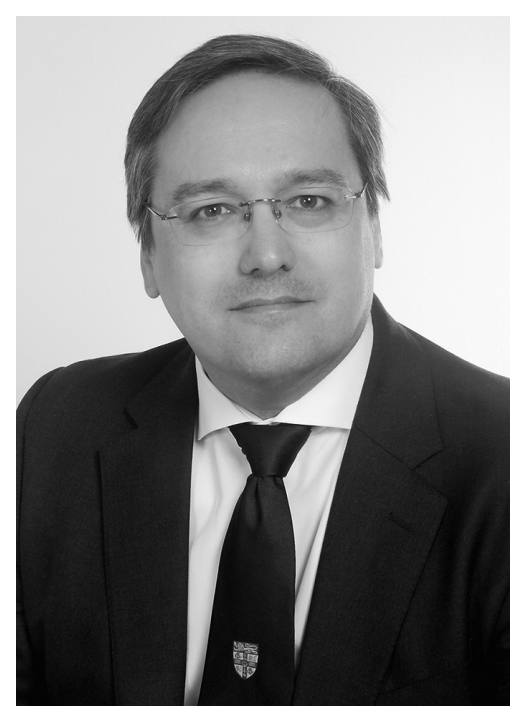

Tim Lane

Editor-in-Chief of the Annals

A very warm welcome to this the latest edition of the Annals. May I wish you all a happy New Year! 2020 is set to represent an exciting time for the Royal College of Surgeons with the expected completion of Project Transform heralding a much anticipated return to the reconfigured Barry Building. I am particularly thankful for the continued hard work of all the team at the Annals and especially for their on-going support and encouragement. Many of our regular team members have recently moved on to pastures new where they are pursing fresh challenges. As a result, we currently find ourselves somewhat depleted in number. Because of this, our remaining stalwarts have had to take on a number of additional roles for which I am most grateful. Like many of the full-time staff within the College, the team at the Annals have also had to lead a rather nomadic existence in the Nuffield Building during this period of renewal and so I am additionally indebted to them all for their forbearance during this time.

A few of us will have been fortunate enough to have been afforded at least a little time with friends and family over the festive period. For many of us, however, the opportunity to attend such traditional gatherings with kith and kin is suppositional to say the least. More often than not it represents the exception to the rule. However, when such opportunities do arise they often provide for a period of reflection - the denouement of which is usually a baneful musing upon on our own regrettable work-life balance. A protracted period of contemplation is however seldom healthy and mercifully we are all too soon absorbed once more into gruelling and forensically monitored job-plans which guard against such prolonged and harmful periods of rumination.

There are however many of our colleagues who have necessarily been forced to consider their long-term commitment to the NHS as a result of the pensions debacle. The grotesqueness of a situation which sees continued employment erode a personal provision for income in retirement and a situation which has seen individuals required to pay tens of thousands of pounds in taxation in the absence of any net income, is clearly perverse. The consequences of this have been early retirements, reduced hours and resignations. The egress of junior doctors following the contract imposition in recent years has now been replaced by a haemorrhage of the professions most senior clinicians. We have entered the eye of a perfect storm. The Health Services Journal, in a discerning Editorial, has described this unparalleled scenario as a 'black swan' event which has signalled an exodus of clinicians from the workforce. ${ }^{1}$ More concerning than this, however, is that it also heralds the breakdown of the established 'psychological contract' with the NHS from its remaining doctors. As surgeons have sought to mitigate the disastrous consequences of the pension changes, they have explored new ways of working. Some have reduced their hours. Others have chosen early retirement whilst others still have adopted part-time contracts. Having adjusted to the significant financial penalty which accompanies a reduction in worked hours, many have discerned that this new balance between clinical commitments and life outside of surgery (apparently there is one) is curiously appealing. Even if a suitable solution is eventually found to the current situation, many of our colleagues will never return to previously established patterns of working. For these individuals, Pandora's box has well and truly been opened. By glimpsing into this mythical container some have seen the chance for a different future. A future which no longer includes excessive hours, onerous on-call commitments and an actuarial survival rate which predicts that many will not live long enough to receive the income from a pension scheme upon which they have already been taxed. For those graduates entering the clinical arena for the first time, there is much evidence to suggest that many no longer see their long-term future within the profession. This new generation of clinicians are unlikely to accept at face value the contractual reassurances which their predecessors have accepted (to their detriment) and which are so regularly rescinded and replaced with breath-taking ease by successive governments. The Department of Health's plans to bolster the flagging workforce by increasing medical school places (though ultimately welcome) appears feeble in comparison. It is no more efficacious in the short term than watching a dripping tap 
attempting to fill a bath from which the plug has already been pulled.

The classicists amongst you will know that after Pandora's box was opened there was just one thing left after all the sickness and evil had been released into the world. Hope. If there really is hope left, then it will be in how we encourage NHS Trusts to adopt a new approach to employing many of our most experienced of surgeons. In a recent Bulletin Editorial ${ }^{2}$ Neil Mortenson makes the case for a more enlightened approach to encouraging our senior colleagues to remain within the profession where they can continue to provide that corporate and institutional wisdom. It will require a more 'friendly' approach by NHS Trusts to those surgeons agreeable to working beyond classic retirement age and to demonstrate a pliancy for which it has not previously been noted for.

It is perhaps beholding upon me to provide some editorial balance at this stage and point out that there are other classical scholars who have adopted a more literal interpretation of that which remained in Pandora's box after it was opened in the home of Epimetheus. An alternative interpretation of the term 'hope' is that of 'deceptive expectation'. Some might even argue that that it is a more realistic reflection of the current situation. Nevertheless, at the beginning of this another New Year, I choose to affiliate myself with the former rather than the latter - but more out of hope than expectation.

\section{References}

1. What if the doctors never come back? Alastair McLellan. Health Services Journal. (Comment) $18^{\text {th }}$ November 2019

2. The 100-year surgical life. Neil Mortenson. The Bulletin of the Royal College of Surgeons of England (2019) 101 (7) 256. 